\title{
A Study on the Slope Failure Monitoring of a Model Slope by the Application of a Displacement Sensor
}

\author{
Sungyong Park, ${ }^{1}$ Hyuntaek Lim, ${ }^{2}$ Bibek Tamang $\mathbb{D}^{2},{ }^{2}$ Jihuan Jin, ${ }^{2}$ Seungjoo Lee, ${ }^{2}$ \\ Sukhyun Chang, ${ }^{2}$ and Yongseong Kim $\mathbb{D}^{2}$ \\ ${ }^{1}$ Citizens Safety Division, Yongin City Hall, Gyeonggi 17019, Republic of Korea \\ ${ }^{2}$ Department of Regional Infrastructure Engineering, Kangwon National University, Chuncheon 24341, Republic of Korea \\ Correspondence should be addressed to Yongseong Kim; yskim2@kangwon.ac.kr
}

Received 24 September 2019; Revised 9 November 2019; Accepted 27 November 2019; Published 21 December 2019

Academic Editor: Abdellah Touhafi

Copyright (C) 2019 Sungyong Park et al. This is an open access article distributed under the Creative Commons Attribution License, which permits unrestricted use, distribution, and reproduction in any medium, provided the original work is properly cited.

\begin{abstract}
Many causalities and economic losses are caused by natural disasters, such as landslides and slope failures, every year. This suggests that there is a need for an early warning system to mitigate casualties and economic losses. Most of the studies on early warning systems have been carried out by predicting landslide-prone areas, but studies related to the prediction of landslide occurrence time points by the real-time monitoring of slope displacement are still insufficient. In this study, a displacement sensor and an Internet of Things (IoT) monitoring system were combined together, to monitor slope failure through cutting experiments of a real-scale model slope. Real-time monitoring of the slope movement was performed simultaneously via a low-cost, efficient, and easy-to-use IoT system. Based on the obtained displacement data, an inverse displacement analysis was performed. Finally, a slope instrumentation standard was proposed based on the slope of the inverse displacement for early evacuation before slope failure.
\end{abstract}

\section{Introduction}

The mountain ranges in South Korea can be classified into two categories based on the modes of formation. The primary mountain ranges are formed by tectonic activities, and the secondary mountain ranges are formed by erosional processes $[1,2]$. Similarly, many hills and mountains have been formed by fluvial processes, which consist of sediments from various quaternary age deposits [2]. Some slopes in Korea consist of a top layer of permeable soil with a shallow depth of less than $1 \mathrm{~m}$, and most of the slopes are composed of impermeable rocks. More than $78 \%$ of the cut slopes are rocky slopes in Korea, and about $79 \%$ of landslide-prone slopes are rock slopes [3]. Similarly, natural slopes consisting weathered soils are other types of predominant slopes. So most of the natural slopes in Korea are structurally weak and are prone to landslides particularly in rainy seasons. This suggests that landslide monitoring is a paramount necessity to reduce causalities and mitigate economic loss due to landslides.
There has been an increase in fatalities and economic losses due to natural disasters, such as landslides and slope failures, worldwide [4-9]. In the case of South Korea, the damages caused by landslides occur mainly from July to September, the period when typhoons and heavy rainfalls occur frequently, every year. Recently, there have been significant landslide damages, mainly in heavy rainfall areas, due to the localized heavy rain as a result of global climate change events. Since the landslides caused by extreme climate change events are increasing every year, there is a great need for the development of landslide monitoring technology that can reduce casualties and economic losses due to landslides [10].

The government is promoting policies for the prevention and mitigation of landslide damages by designing early prevention and quick response systems in disaster-prone regions, investigating the causes of disaster recurrence, and strengthening their restoration capacity. In addition, the related organizations are conducting landslide prevention projects through a selection of disaster-prone regions and landslide-prone steep slopes [11]. However, damages due to 
landslides continue to increase, and fundamental solutions are in demand to overcome them. The solution of predicting landslide occurrence time points, rather than the existing solution of predicting landslide occurrence regions, is becoming a prominent practical solution [12].

Many studies on early warning systems for natural and artificial slopes have provided a base for further research on early warning systems [13-16]. Although many studies are being carried out to reduce the damage caused by landslides, it is still difficult to predict landslides [16-18]. Thus, the prediction of landslide occurrence is paramount for issuing landslide warnings and mitigating casualties and property damages. For this reason, the real-time monitoring of landslide-prone slopes is the most efficient method. Although different agencies are conducting intensive research related to the prediction and assessment of landslide risks and solution methods, these studies have so far been carried out to predict and assess landslide occurrence regions. Moreover, there are many studies on early warning systems based on real-time rainfall data $[19,20]$. Some of the methods to predict landslides, such as Time Domain Reflectometry (TDR), Ground Penetrating Radar (GPR), and Frequency Domain Reflectometry (FDR), are expensive and intricate and require high frequency to operate causing hazards to the environment [21]. The preceding studies on landslide prediction using vibration sensors $[22,23]$ may not have enough sensitivity to raise warning system before slope fails, and it may not simulate the real field conditions. However, studies on the prediction of landslide occurrence time points based on displacement measurements are still insignificant in number [24]. Currently, the Ministry of Public Administration and Security and the Korea Forest Service [25] have designed and are operating landslide warning and early warning systems based on real-time rainfall data. In addition, related organizations are carrying out research on instrumentation systems that can detect slope failure in advance and reduce damage. However, the instrumentation systems currently being used in the field have complex structures and require experts to analyse data, and the burden on maintenance due to system operation is increasing. Therefore, the need for a low cost, real-time slope instrumentation system that can detect the occurrence of landslides in advance is growing. The slope instrumentation system should be cheap and easy enough for the local residents to afford and handle [26].

Tamate and Hori [27] used an extensometer, a shear strainmeter, and an inclinometer to measure shear strain in the shallow depth of slope subsurface by excavating a fullscale model slope. The designed warning system had some drawbacks. The warning system used dry cell battery with an average life of 20 days only. But the warning system, proposed in this study, has a rechargeable battery embedded to the main body of the alarm system that is rechargeable by solar energy. This increases the life and efficiency of the warning system, with less need for maintenance. Moreover, the warning system proposed by the previous studies [27-30] was targeted to raise alarm before the slope failure. But the warning system, proposed in this study, is able to receive the slope movement data in real time via a wireless

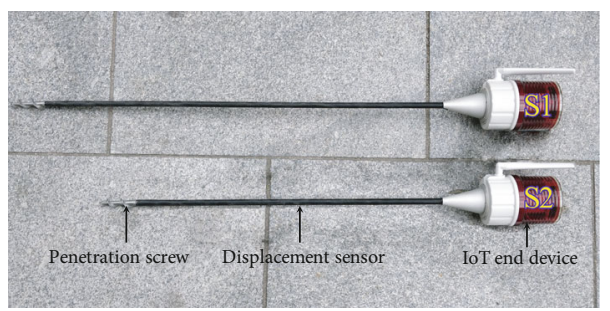

Figure 1: Displacement sensors of $800 \mathrm{~mm}$ and $1000 \mathrm{~mm}$ length.

LoRa network and analyse it. Also, the present study proposes a slope instrumentation standard that can be used as a basic data for a slope monitoring system in the future.

In this study, unlike the existing slope monitoring systems, we designed a low-cost, high-performance subsurface displacement sensor, tested by a field model experiment, which examined its optimum installation position and considered the measures for the prediction of slope failure time points. Henceforth, the prognostic prediction analysis data for slope failure developed in this study can be utilized as a basic disaster risk mitigation technology.

\section{Design of a Subsurface Displacement Sensor}

2.1. Design of a Subsurface Displacement Sensor. The subsurface displacement sensor developed and patented by Tamate [31] has been upgraded in this study. It is composed of a stainless steel pipe with an outer diameter of $10 \mathrm{~mm}$ and a thickness of $1 \mathrm{~mm}$. A strain gauge was attached to the central part of the pipe, which was connected via 2 -active gauge method to generate a response to the bending deformation. A penetration screw of $80 \mathrm{~mm}$ in length was installed on the bottom end of the pipe for easy installation. The outer surface of the displacement sensor was glazed with a final coating agent after attaching the strain gauge, as well as a weather-resistant heat-shrinkable tube, in order to prevent damage to the wire and cable of the strain gauge during its penetration into the model slope. Finally, a waterproof connector that helps to record the response from the strain gauge was connected to the centre of the hexagonal plug. The penetration-type pipe strain gauge patented by Tamate [31] had a sensor and warning system, with an alarm unit, as two separate units were connected by a wire, but the two units, along with the IoT end device, have been assembled into a single, integrated unit in this study, which increases workability in the field. The displacement sensors of different lengths, viz. $800 \mathrm{~mm}$ and $1000 \mathrm{~mm}$, were used in this study, which helps in predicting the depth of the slip surface during failure. Figure 1 shows the displacement sensors used in this study.

2.2. Tests of the Subsurface Displacement Sensor. In this study, a total of two displacement sensors (S1 and S2) were used for slope failure monitoring. The displacement-strain rate responses of each sensor were tested prior to their use in the field. These tests were carried out by considering the cantilever conditions, with one fixed and one free support. The application of the load and measurement of the displacement 


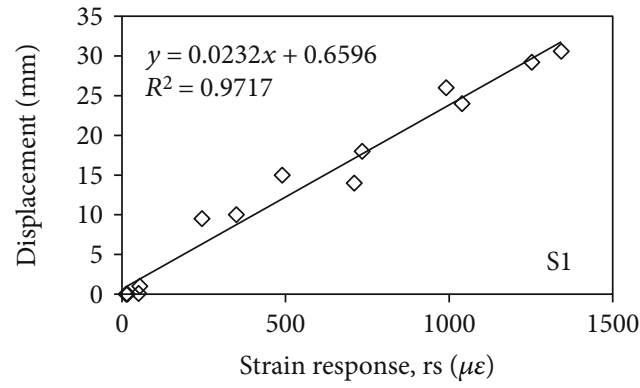

(a)

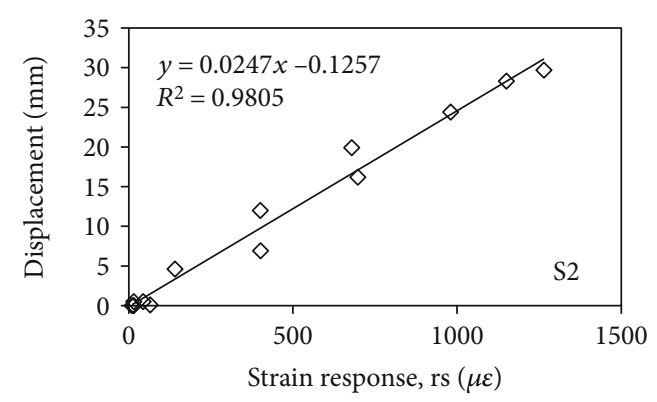

(b)

FIgURe 2: Results of displacement sensor tests: (a) $1000 \mathrm{~mm}$ and (b) $800 \mathrm{~mm}$.

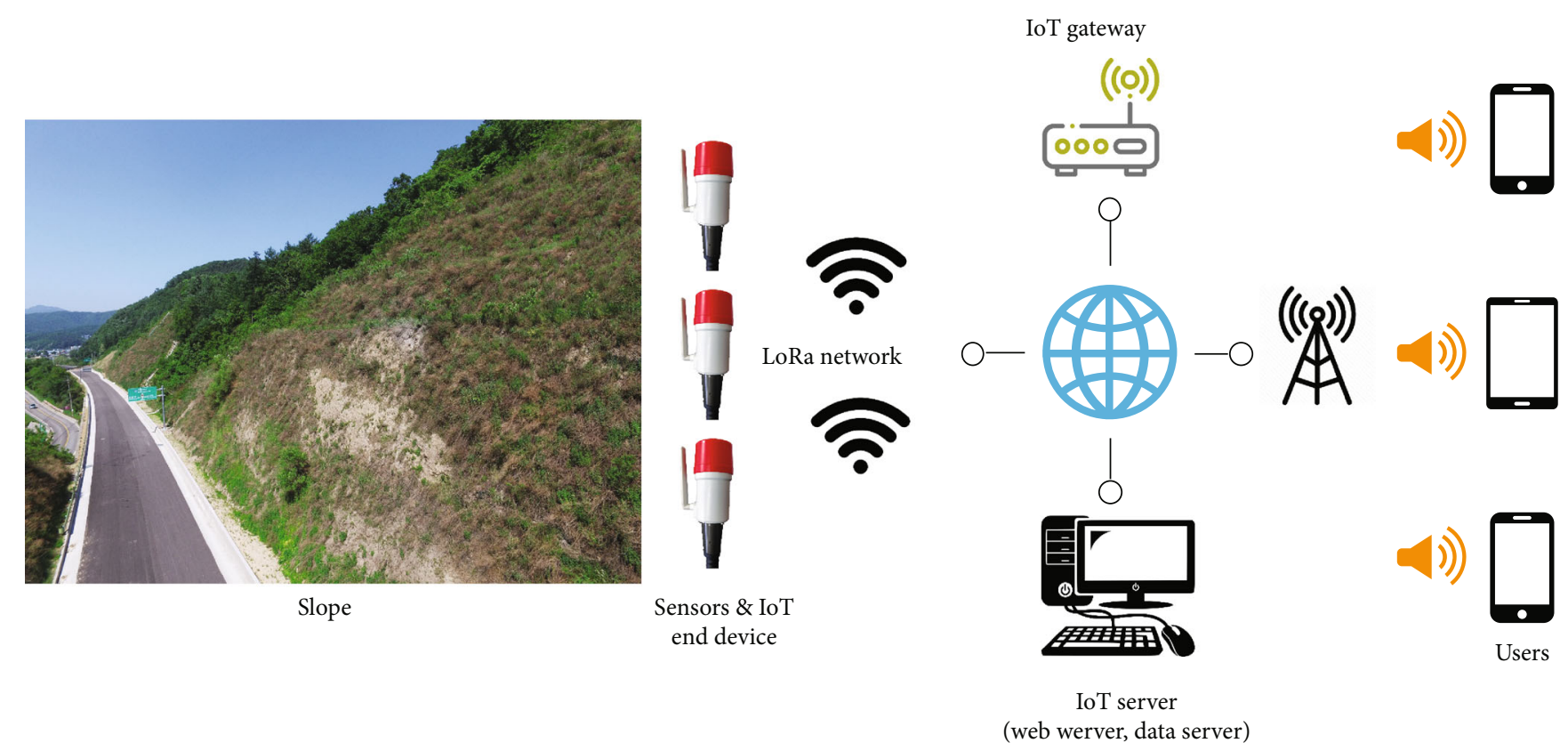

FIgURE 3: Configuration diagram of the monitoring system.

was done at the free end to obtain a displacement-strain response from the applied load.

The trend lines of the test results were found to be approximately linear and expressed as a linear function. In addition, the strain response of the displacement sensor at the free end for various load increments is determined easily, and the result can be applied to the qualitative understanding of the ground displacement behaviour.

In addition, the results of this test confirmed that the strain response due to displacement is somewhat different in either case (refer to Figure 2). This type of phenomenon is considered to be due to the variation of the modulus of deformation for various lengths of the displacement sensor, as well as the heterogeneity of the stainless steel (STS304), which is the main material of the sensor body, and strain gauge joint errors.

\section{Monitoring System}

In order to receive and analyse signals from the sensors, a method using a data logger connected through a wire to monitor the collected signals on a PC via a USB cable is typical [27, 28, 30]. However, this method has limitations in collecting data over a long period of time, and if the area to be observed is wide, a large number of data loggers are required, which is costly and requires significant manpower. Therefore, in this study, we have upgraded the warning system developed by Tamate et al. [27, 28, 30] into a slope monitoring system using the Internet of Things (IoT). The monitoring system, proposed in this study, in which displacement sensors is combined with IoT, is more efficient and easy to monitor slope failure compared to the previous method proposed by Tamate et al. The warning system suggested by the previous studies was able to alert the slope failure only, but the upgraded monitoring system, proposed in this study, can send the slope movement data to the server in real-time through a wireless LoRa network, analyse the received data, and send the slope failure alert to users' smartphones.

An IoT monitoring system consists of a server, a client, and a gateway (Figure 3), and repeaters can be added 


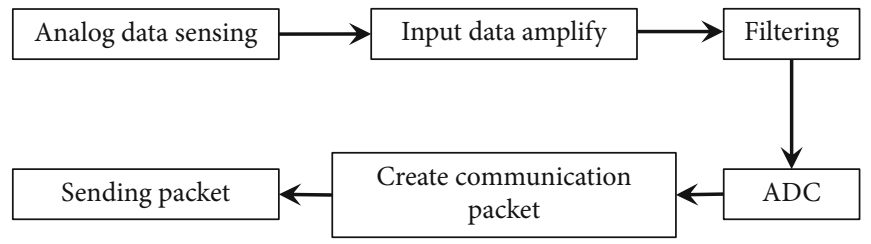

Figure 4: Sensing data flow chart in the IoT client.

when the distance between devices is out of network coverage.

3.1. IoT Client. The designed ground displacement sensor can obtain the changed micro voltage values using a strain gauge whose resistance value changes based on stress. Thus, the IoT client amplifies these types of infinitesimal analog voltage values, passes them through a filter to remove noise, and converts them to digital values through the ADC (Analog-to-Digital Converter). The data packets are then created for the communication protocol through an MCU (Micro Controller Unit) from the digital values obtained from the ADC and are transmitted to the gateway via the LoRa (Long Range) communication module and antenna. The details of designed IoT client and its mainboard are provided in the supplementary files (available here).

Optionally, the failure threshold value set by the server can be recognized, and local people can be alerted, by raising the warning signal. Figure 4 shows the data flow of the sensor values in the IoT client.

The warning system proposed by Tamate and Hori [27] used dry cell battery, three cells in number, as a power supply that had an average running time of 20 days. But the IoT client, proposed in this study, is able to harvest solar energy to power itself. This feature, in particular, increases the efficiency and life of the whole system and has a minimum running time of 1 year and can run more if proper sunlight is available.

3.2. IoT Gateway. The IoT gateway plays the role of facilitating smooth communication between the client and the server and can reduce the communication cost. It can also provide various communication flows through the private network configuration and can possess client management capabilities and features that allow clients to be automatically configured as meshes.

3.3. IoT Server. An IoT server connects to the Internet, collects data from the sensor, and monitors the status of the IoT client. It provides various intuitive user interface (UIs) for the convenience of administrators and manages the database securely and efficiently. Dell PowerEdge T440 was used as the IoT server, and its hardware specifications are provided in the supplementary files (available here).

\section{Execution of the Field Model Experiment}

4.1. Design of the Field Model Slope. The model slope was constructed by filling the soil, and then the field experiment was performed by cutting the slope. The height limit of the slope cutting was studied through numerical analysis, and the model slope was designed to reflect the results from the numerical analysis during the real-scale field model experiment.

The slope height was $5 \mathrm{~m}$ and $4 \mathrm{~m}$, and the crest length was $6.65 \mathrm{~m}$ and $5.32 \mathrm{~m}$ in case 1 and case 2, respectively. The angle of inclination of the slope was $60^{\circ}$ in both cases (Figure 5). To simulate slope failure, the final cut section, $\mathrm{C} 4$, was selected $(1.0 \mathrm{~m}$ and $0.8 \mathrm{~m}$ below the crest line of the slope), considering the fact that increasing the slope height increases the slope distance. In all cases, the same test conditions were applied to all the cut sections, and the waiting time was given after each cutting in order to analyse the slope movement behaviour during cutting.

Weathered granite soil, used in the model experiment, is the most widely distributed soil throughout South Korea. Soil, like gneiss, is weathered into residual soil by various factors and is used in construction sites as a filling material or as a high-quality base material. Depending on the progress of weathering, the voids in the soil particles are well developed, and large deformation occurs when the load is applied.

The soil used in this study has a density of $17.9 \mathrm{kN} / \mathrm{m}^{3}$, a fine content of $11.5 \%$, and a $D_{50}$, diameter corresponding to $50 \%$ finer, of $0.85 \mathrm{~mm}$. This soil is classified as SW according to the Unified Soil Classification System (USCS) (i.e., sand with good particle size distribution; Table 1). To simulate the unsaturated state of soil material, water content obtained through the field density test and compaction tests was adjusted and applied in the field test.

A backhoe was used for the construction of the model slope. The backhoe did not climb up the slope, and no compaction was applied by the bucket of the backhoe. The model slope was constructed by applying only the self-weight of the soil, in order to reproduce natural deposition conditions.

4.2. Installation of the Subsurface Sensor. Figure 6 shows the installation process of the subsurface displacement sensors on the model slope surface. The designed displacement sensors were installed perpendicular to the slope surface using the penetration screws attached to the lower portion of the sensor, and the sensors were installed at a horizontal spacing of $1.77 \mathrm{~m}$ and $2.22 \mathrm{~m}$ in case 1 and case 2, respectively (Figure 5).

The data obtained from the subsurface sensors were automatically recorded by the monitoring system using the Internet of Things (IoT) through the connector at the upper portion of the sensor.

4.3. Simulation of Slope Failure through Slope Cutting. In this study, the slope failure behaviour was observed by stepwise cutting starting from the toe of the slope. The cutting 

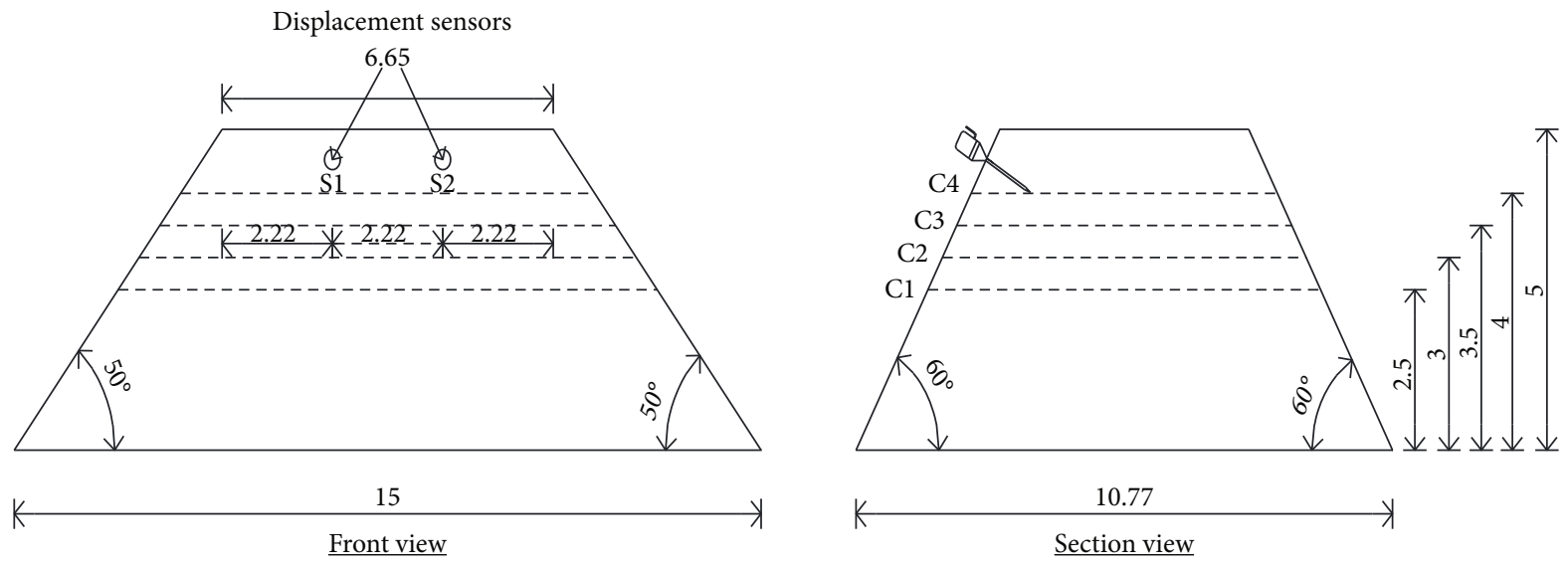

Case 1

(a)
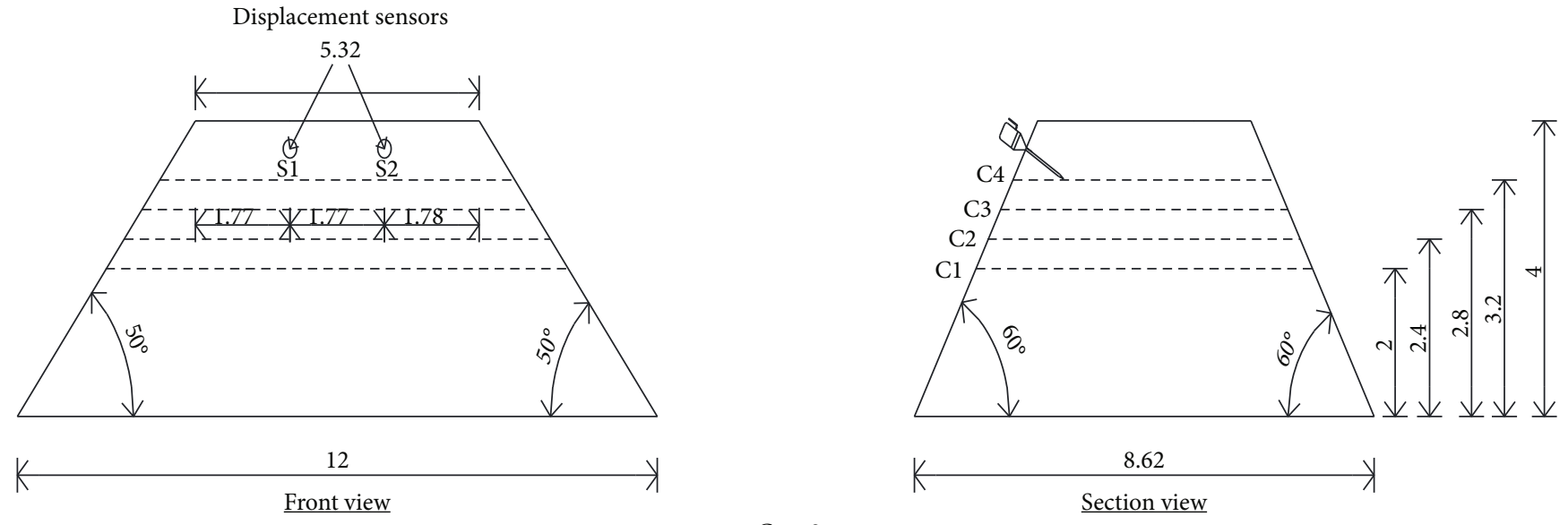

Case 2

(b)

Figure 5: A schematic diagram of the model slope: (a) case $1(H=5 \mathrm{~m})$ and $(\mathrm{b})$ case $2(H=4 \mathrm{~m})$.

TABLE 1: Physical properties of the soil used in the study.

\begin{tabular}{lcccccc}
\hline$\rho_{\mathrm{s}}\left(\mathrm{kN} / \mathrm{m}^{3}\right)$ & $\begin{array}{c}\text { Sand } \\
(\%)\end{array}$ & $\begin{array}{c}\text { Silt } \\
(\%)\end{array}$ & $\begin{array}{c}\text { Clay } \\
(\%)\end{array}$ & $\begin{array}{c}D_{50} \\
(\mathrm{~mm})\end{array}$ & $\begin{array}{c}\rho_{\mathrm{dmax}} \\
\left(\mathrm{kN} / \mathrm{m}^{3}\right)\end{array}$ & $\begin{array}{c}w_{\text {opt }} \\
(\%)\end{array}$ \\
\hline 17.9 & 57.5 & 10.0 & 1.5 & 0.85 & 19.3 & 13.0 \\
\hline
\end{tabular}

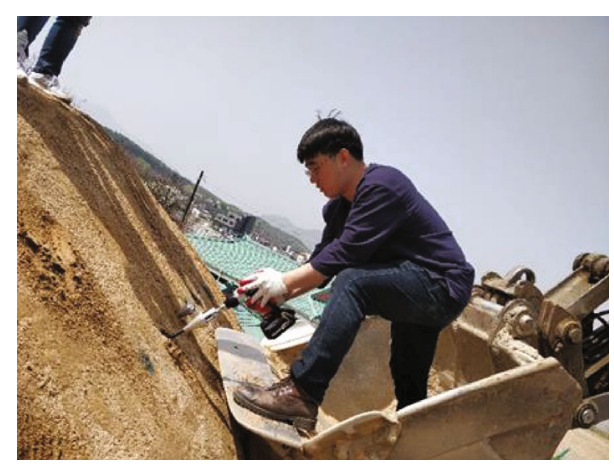

FIgURE 6: Drilling subsurface deformation sensors. operation was carried out in four steps, from $\mathrm{C} 1$ to $\mathrm{C} 4$, such that the cut surface was vertical. The time required for each cut, including the waiting time after the cutting process, was 9 minutes for case 1 and 6 minutes for case 2, and continuous measurements were performed to include changes between two consecutive cuts. The displacement data were recorded at an interval of one second, whereas the shear strain data were collected at an interval of 10 seconds in the previous study [27]. The model slope for both the cases is shown in Figure 7, and the slope failure is shown in Figure 8.

\section{Analysis of Experiment Data}

5.1. Slope Movement over Time. Figure 9 shows the timedependent displacement distribution of slope failure during slope cutting of $5 \mathrm{~m}$ (case 1) and $4 \mathrm{~m}$ (case 2) slope heights, respectively. The horizontal axis shows the elapsed time in minutes, and the vertical axis shows the ground displacement in millimeters.

In case 1 (Figure 9(a)), the S1 sensor (1000 mm length) showed infinitesimal displacement during $\mathrm{C} 1$ cut section and showed some precursors during waiting time of $\mathrm{C} 2$ 


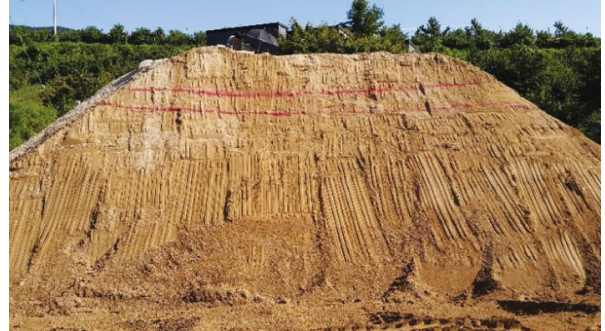

(a)

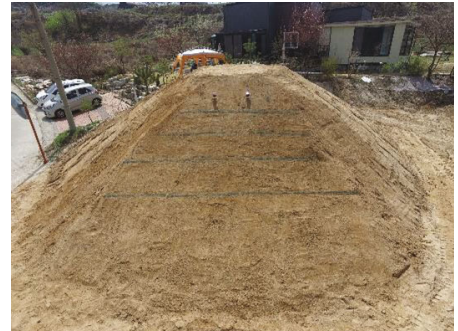

(b)

Figure 7: Model slope: (a) case 1 and (b) case 2.

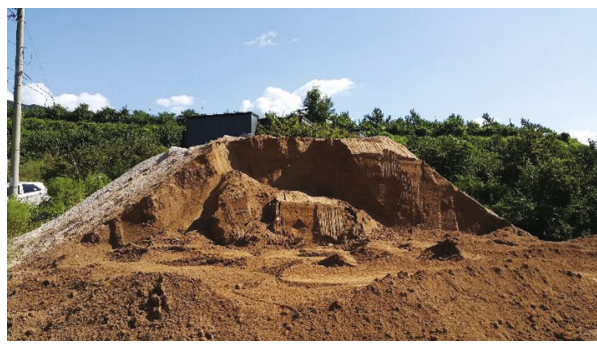

(a)

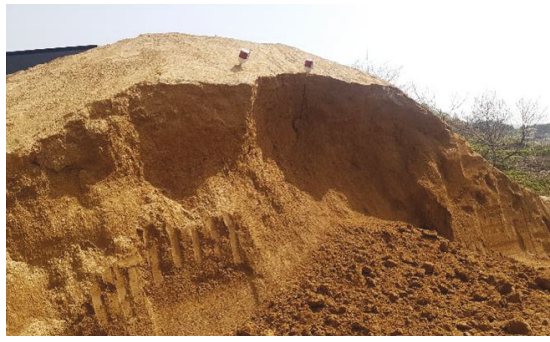

(b)

Figure 8: Slope failure: (a) case 1 and (b) case 2.

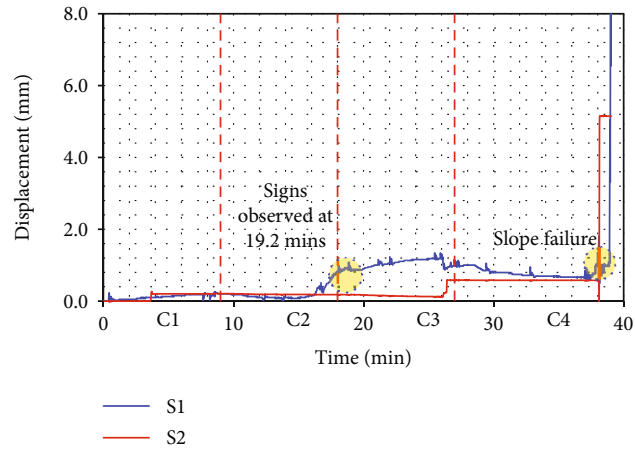

(a)

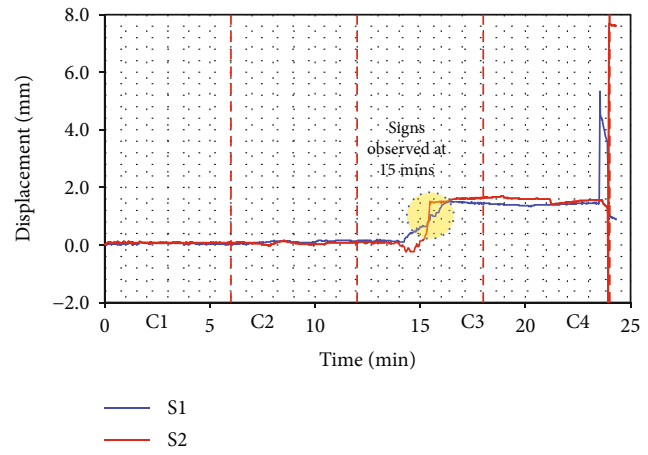

(b)

FIgURE 9: Displacement-time graph: (a) case 1 and (b) case 2.

cut section. This slope behaviour can be considered to be identical to the plastic deformation prior to slope failure observed by Tamate and Hiro [27]. Tamate and Hiro [27] referred it as the first failure, whereas it is considered signs or precursors before the final slope failure. Since the slope maintained its stability until this point, it was vague to consider this point as a slope failure. Then the displacement was almost constant till C4 cut section. Similar reactions were observed by the experiments performed by Tamate and Hiro [27] after the signs were observed. Finally, the displacement value surged instantaneously, and finally, the slope failure occurred at 33.9 minutes. However, the S2 sensor ( $800 \mathrm{~mm}$ length) did not show noticeable displacement until the C3 cutting and showed some displacement during waiting portion of the C3 cutting. The displacement value remained constant after then, and slope failure occurred suddenly at 33.9 minutes.

In case 2 (Figure 9(b)), both the sensors, S1 and S2, showed almost similar behaviour. The precursors of slope failure were observed at about 15-16 minutes, and then almost constant displacement values were observed. Finally, the slope failure occurred abruptly at about 23-24 minutes.

In both cases, the slope failure phenomenon could not be clearly measured by the S2 sensor ( $800 \mathrm{~mm}$ length) since there was no proper ground movement before the slope failure. So the suitable length of the displacement sensor for the prediction of slope failure, in this study, can be considered to be about $1000 \mathrm{~mm}$. Hence, the length of the displacement sensor should be designed by considering the anticipated depth of the slip surface during slope failure. 


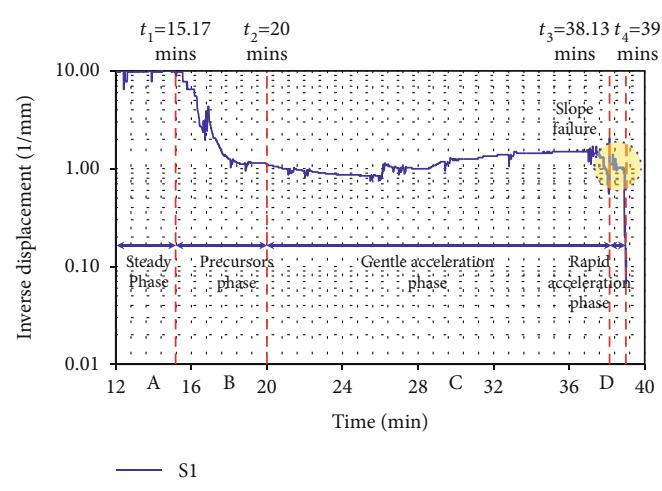

FIGURE 10: Inverse displacement-time graph for case 1.

5.2. Identification of Failure Signs through Inverse Displacement Analysis. Voight [32] proposed a method of estimating the slope failure time using the inverse slope displacement and displacement velocity over time. Likewise, Tamate et al. [27-30] studied the relationship between the risk of slope failure and increase in the shear strain in the shallow slope surface. The previous studies by Tamate et al. [28-30] used the inverse of shear strain for the prediction of slope failure, whereas, in this study, the inverse of slope displacement has been considered for monitoring slope failure.

This study was performed to analyse the slope failure behaviour using inverse displacement (1/displacement) over time via the analytical method mentioned above. Since in case 2 no clear time-dependent slope movement was observed during the application of the inverse displacement, the analysis was done for case 1 only, for which the slope failure behaviour was clearly observed. Here, data from only the S1 sensor of case 1 was used for analysis as the S2 sensor could not confirm the final failure phenomenon during the slope cutting experiment.

Figure 10 shows the displacement value measured by the S1 sensor converted in terms of the inverse displacement. The horizontal axis shows the time elapsed from 12 minutes, at which the slope movement was observed, to 40 minutes, at which the experiment was ended, and the vertical axis shows the inverse displacement.

It is observed that there is no change in slope movement until 15.17 minutes, and some infinitesimal displacement values recorded until this time point are not considered in the analysis because they are regarded as the noise of the electrical signal generated during transmission of the displacement data and the vibrations caused by the excavation equipment (i.e., the backhoe).

In section $B\left(t_{1}-t_{2}\right)$ of Figure 10 , a sudden inverse displacement was observed during waiting section of C2 cutting stage and the beginning of the C3 cutting stage. Since the slope at this time was calculated as $1.59 / \mathrm{mm} / \mathrm{min}$, it was considered the onset of slope instability. The slope of the $\mathrm{C}$ section $\left(t_{2}\right.$ to $\left.t_{3}\right)$ significantly decreased to $0.03 / \mathrm{mm} / \mathrm{min}$ compared to section $\mathrm{B}$. This suggests that the reaction of the slope instability that occurred in section B is continuously maintained. At the $\mathrm{D}$ section $\left(t_{3}-t_{4}\right)$, which is the waiting section after the completion of $\mathrm{C} 4$ cutting, the slope failure
TABLE 2: Proposal for an instrumentation standard.

\begin{tabular}{lccc}
\hline Steps & $\begin{array}{c}\text { Level of } \\
\text { severity }\end{array}$ & $\begin{array}{c}\text { Cumulated } \\
\text { displacement }(\mathrm{mm})\end{array}$ & $\begin{array}{c}\text { Slope of inverse } \\
\text { displacement } \\
(1 / \mathrm{mm} / \mathrm{min})\end{array}$ \\
\hline Step 1 & Normal & 0 & 0 \\
Step 2 & Cautious & 0.89 & 1.59 \\
Step 3 & Alert & 1.52 & 0.03 \\
Step 4 & Critical & 10.31 & 2.25 \\
\hline
\end{tabular}

occurred by a geometric increase of the slope with a value of $2.25 / \mathrm{mm} / \mathrm{min}$ just before the slope failure.

Inverse displacement value decreased as the slope movement increased, and a creeping tendency was observed before the failure. In other words, the primary slope movement was observed which is characterized by a rapid and instantaneous decrease in the inverse displacement value. Thereafter, a constant decreasing tendency was maintained. Finally, the secondary slope movement, in which the inverse displacement decreases geometrically, was monitored. As a result of this experiment, a sign of slope failure was first monitored 14.7 minutes prior to the failure, and the secondary behaviour, which gave rise to the final failure, could be monitored 0.87 minutes prior the final failure.

5.3. Proposal for a Slope Instrumentation Standard. The previous studies [27-30] were targeted to raise a warning system before slope failure. But this study generalizes the slope movement behaviour and proposes a slope instrumentation standard, so that it can be a basis for slope monitoring. This study uses inverse displacement data for predicting slope failure, whereas the previous studies used inverse shear stain. If the change in inverse displacement is examined, the slope of inverse displacement becomes slightly steep in the precursor stage and then decreases at a constant rate in the gentle acceleration phase. In the case of the secondary slope movement phase, the inverse displacement shows a geometric decrease, and then the emergency situation is monitored, during which the final failure has occurred. Here, the section requiring evacuation prior to slope failure features a gentle acceleration after the sign of failure is detected.

In this study, a change in inverse displacement was observed in the precursor phase. We proposed a slope instrumentation standard for an early warning system that warns when slope failure conditions are progressing (Table 2). Figure 10 shows the concept of inverse displacement for the prediction of slope failure.

Based on cumulative displacement and slope of inverse displacement, a slope instrumentation standard is proposed. The proposed instrumentation standard defines different levels of severity according to the cumulative displacement and slope of inverse displacement. We classified the section before occurrence of signs as the steady phase, the point at which signs are seen as the precursor phase, the section with a constant decrease in slope as the gentle acceleration phase, and the phase in which the secondary slope movement or geometric decrease in the inverse displacement occurs as the rapid acceleration phase (Table 2). The rapid acceleration 
phase can be defined as a critical state that leads to the final slope failure. Therefore, the evacuation should be completed prior to reaching the rapid acceleration phase in order to reduce casualties. In an inevitable case, the evacuation must be completed within the rapid acceleration phase right before the final failure.

However, since the proposal of slope instrumentation standard is based on a one-time experiment, it is necessary to ensure the system's reliability through additional field experiments and slope failure case data in the days to come.

\section{Conclusions}

In this study, a displacement sensor designed and patented by Tamate et al. was upgraded to predict the slope movement during a landslide, and slope failure behaviour was investigated by a field cutting model tests. The conclusions obtained from this study are as follows:

(1) When the length of the displacement sensor is less than $800 \mathrm{~mm}$, characteristics like the precursor phenomena and slope failure were not clearly observed and were difficult to be used as data for predicting slope failures. Thus, the suitable length of the displacement sensor should be designed by considering the anticipated depth of the slip surface, and the suitable length of displacement sensor in this study was $1000 \mathrm{~mm}$

(2) The risk of failure increases as the slope of the inverse displacement increases during the course of the slope failure. The precursor phase, the gentle acceleration phase, and the final failure phase can be quantified by numerical values and the slope of the inverse displacement

(3) Based on the slope of the cumulative displacement and inverse displacement, a slope instrumentation standard is proposed, and its reliability can be obtained through additional field experiments and slope failure case data in the future

In the future, it will be necessary to establish definite and analytical techniques for the prediction of precursor phenomena suitable to Korean terrain through experiments on various ground conditions. These results can help establish evacuation management standards for steep slopes and revitalize the related instrumentation industry, which provides important disaster prevention technology.

\section{Data Availability}

The excel data used to support the findings of this study are included within the supplementary information file(s).

\section{Conflicts of Interest}

The authors declare that there is no conflict of interest regarding the publication of this paper.

\section{Acknowledgments}

This work was supported by Korea Institute of Planning and Evaluation for Technology in Food, Agriculture, Forestry (IPET) through Advanced Production Technology Development Program, funded by Ministry of Agriculture, Food and Rural Affairs (MAFRA) (116114-03).

\section{Supplementary Materials}

Supplementary Excel File: the displacement value recorded by sensors S1 and S2. The data provided in the excel file can be used to reproduce the graph in Figure 9. The inverse of displacement from sensors S1 and S2 can be used to reproduce the graph in Figure 10. Supplementary Word File: (1) gateway and its specifications, (2) specifications of the IoT Client, and (3) Dell PowerEdge T440 (IoT server) and its specifications. (Supplementary Materials)

\section{References}

[1] H. J. Kwon, "Mountain ranges of Korea," Journal of the Korean Geographical Society, vol. 35, no. 3, pp. 389-400, 2000.

[2] K. Park, "Development in geomorphology and soil geography: focusing on the Journal of the Korean Geomorphological Association," Journal of the Korean Geographical Society, vol. 47, no. 4, pp. 474-489, 2012.

[3] M. I. Kim and G. C. Jeon, "Characterization of physical factor of unsaturated ground deformation induced by rainfall," The Journal of Engineering Geology, vol. 18, no. 2, pp. 127-136, 2008.

[4] J. I. Barredo, "Normalised flood losses in Europe: 1970-2006," Natural Hazards and Earth System Sciences, vol. 9, no. 1, pp. 97-104, 2009.

[5] European Environment Agency, Mapping the impacts of natural hazards and technological accidents in Europe: An overview of the last decade, Publications Office of the European Union, 2011.

[6] EM-DAT The OFDA/CRED International Disaster Database, Université Catholique de Louvain, Brussels, Belgium, 2019, https://www.emdat.be/.

[7] L. Alfieri, P. Salamon, F. Pappenberger, F. Wetterhall, and J. Thielen, "Operational early warning systems for waterrelated hazards in Europe," Environmental Science \& Policy, vol. 21, pp. 35-49, 2012.

[8] L. Piciullo, M. Calvello, and J. M. Cepeda, "Territorial early warning systems for rainfall-induced landslides," Earth-Science Reviews, vol. 179, pp. 228-247, 2018.

[9] I. T. Yang, T. D. Acharya, and D. H. Lee, "Landslide susceptibility mapping for 2015 earthquake region of Sindhupalchowk, Nepal using frequency ratio," Korean Journal of Geomatics, vol. 34, no. 4, pp. 443-451, 2016.

[10] Y.S. Kim, "Development of slope failure forecasting and warning system," Research Institute Report (in Korean), 2015.

[11] Y.-W. Sawng, D.-H. Lim, B.-G. Chae, and J. Choi, "Business ecosystem-focused commercialization strategy for real-time monitoring and detection technology for landslides," Journal of Engineering Geology, vol. 26, no. 2, pp. 223-233, 2016.

[12] Korea Institute of Geoscience and Mineral Resources, Development of an integrated early detection system of landslides based 
on a real-time monitoring, Ministry of Science, ICT and Future Planning, 2014.

[13] C. Atzeni, M. Barla, M. Pieraccini, and F. Antolini, "Early warning monitoring of natural and engineered slopes with ground-based synthetic-aperture radar," Rock Mechanics and Rock Engineering, vol. 48, no. 1, pp. 235-246, 2015.

[14] B. Thiebes, R. Bell, T. Glade et al., "Integration of a limitequilibrium model into a landslide early warning system," Landslides, vol. 11, no. 5, pp. 859-875, 2014.

[15] E. Intrieri, G. Gigli, F. Mugnai, R. Fanti, and N. Casagli, "Design and implementation of a landslide early warning system," Engineering Geology, vol. 147, pp. 124-136, 2012.

[16] A. Vaziri, L. Moore, and H. Ali, "Monitoring systems for warning impending failures in slopes and open pit mines," Natural Hazards, vol. 55, no. 2, pp. 501-512, 2010.

[17] G. F. Wieczorek and J. B. Snyder, "Monitoring slope movements," in Geological Monitoring, R. Young and L. Norby, Eds., pp. 245-271, GSA, Boulder, Colorado, USA, 2009.

[18] T. Uchimura, I. Towhata, L. Wang, and I. Seko, "Development of low-cost early warning system of slope instability for civilian use," in Proceedings of the Proceedings of the 17th International Conference on Soil Mechanics and Geotechnical Engineering: The Academia and Practice of Geotechnical Engineering, vol. 3, pp. 1897-1900, 2009.

[19] D. K. Keefer, R. C. Wilson, R. K. Mark et al., "Real-time landslide warning during heavy rainfall," Science, vol. 238, no. 4829, pp. 921-925, 1987.

[20] R. L. Baum and J. W. Godt, "Early warning of rainfall-induced shallow landslides and debris flows in the USA," Landslides, vol. 7, no. 3, pp. 259-272, 2010.

[21] S. L. SU, D. N. Singh, and M. S. Baghini, "A critical review of soil moisture measurement," Measurement, vol. 54, pp. 92-105, 2014.

[22] S. Biansoongnern, B. Plungkang, and S. Susuk, "Development of low cost vibration sensor network for early warning system of landslides," Energy Procedia, vol. 89, pp. 417-420, 2016.

[23] E. S. B. Ismail, M. H. Habaebi, M. Ibrahimy, and M. R. Islam, "Low-cost vibration chamber for landslide sensory and alarm system," Indonesian Journal of Electrical Engineering and Computer Science, vol. 10, no. 1, pp. 110-119, 2018.

[24] Korea Institute of Geoscience and Mineral Resources, Technology development of landslide rapid detection based on a real-time monitoring, Ministry of Science, ICT and Future Planning, 2015.

[25] Korea Forest Service, A Study on Integrated Management for Hazards of Landslide, Korea Forest Service, 2013.

[26] I. Towhata, T. Uchimura, and C. Gallage, "On early detection and warning against rainfall-induced landslides (m129)," in Landslides, pp. 133-139, Springer, Berlin, Heidelberg, 2005.

[27] S. Tamate and T. Hori, "Study on monitoring for detection of potential risk of slope failure for labor safety," Proceedings of the Geo-Risk 2017, 2007, pp. 267-279, American Society of Civil Engineers (ASCE), 2007.

[28] S. Tamate, T. Hori, C. Mikuni, K. Itoh, N. Kikkawa, and N. Suemasa, "A large scale model test on detection of potential risk of slope failure by monitoring of shear strain in shallow section," Journal of Japan Society of Civil Engineers, Ser. C (Geosphere Engineering), vol. 69, pp. 326-336, 2013.

[29] S. Tamate and K. Itoh, "Monitoring of shear strain in shallow sections of slopes to detect increased risk of slope failure," in Proceedings of the Proceedings of the 17th International
Conference on Soil Mechanics and Geotechnical Engineering, pp. 2143-2146, 2009.

[30] S. Tamate, T. Hori, C. Mikuni, and N. Suemasa, "Experimental analyses on detection of potential risk of slope failure by monitoring of shear strain in the shallow section," in Proceedings of the 18th International Conference on Soil Mechanics and Geotechnical Engineering, pp. 1901-1904, Paris, 2013.

[31] S. Tamate, "Penetration-type pipe strain gauge," US Patent No. 7,762,143, issued July 27, 2010.

[32] B. Voight, "A method for prediction of volcanic eruptions," Nature, vol. 332, no. 6160, pp. 125-130, 1988. 


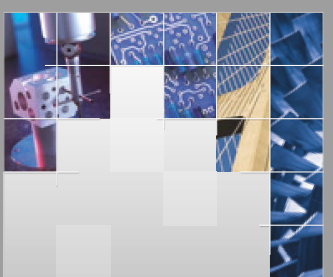

\section{Enfincering}
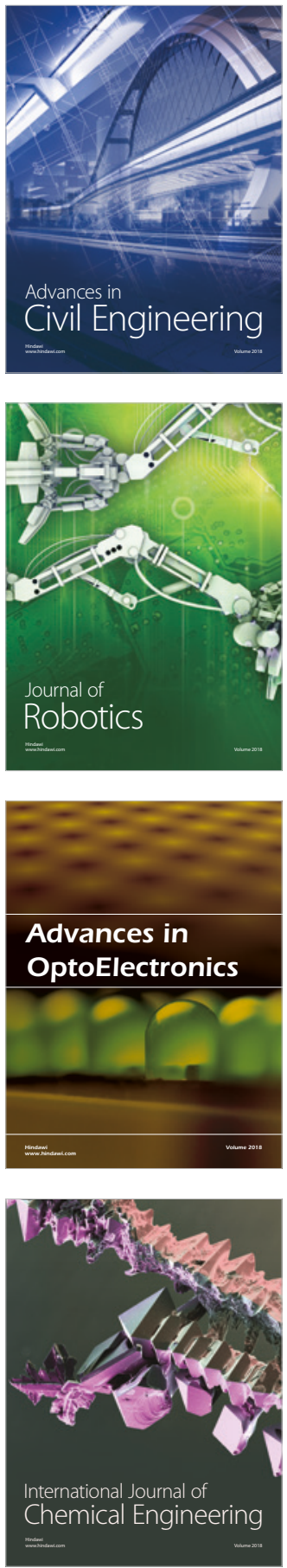

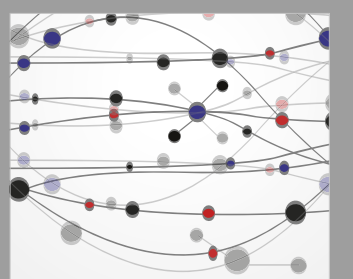

\section{Rotating \\ Machinery}

The Scientific World Journal

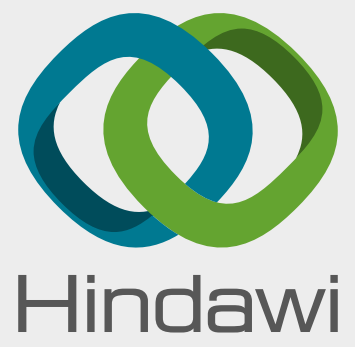

Submit your manuscripts at

www.hindawi.com
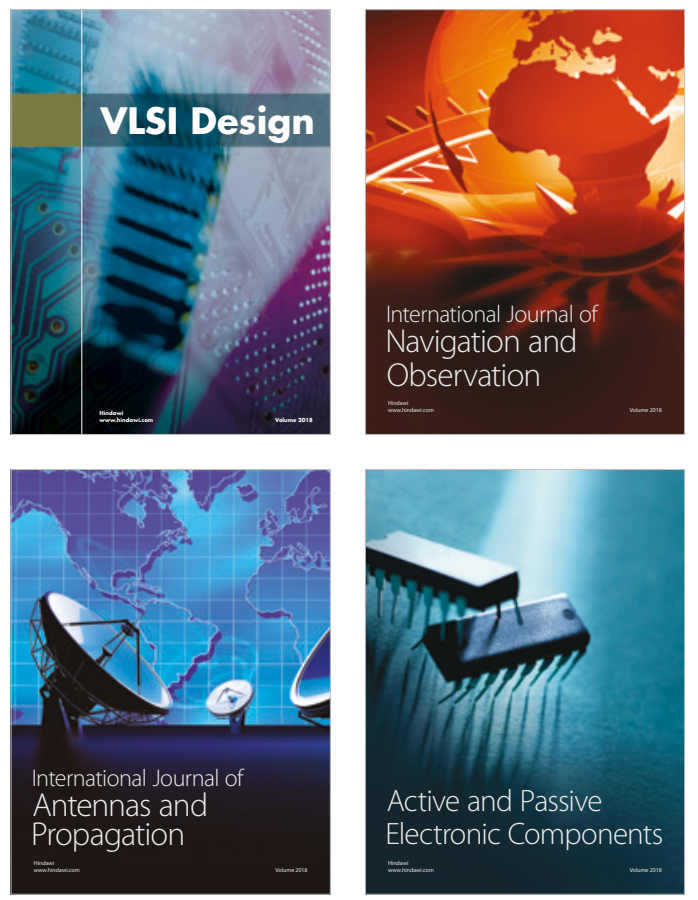
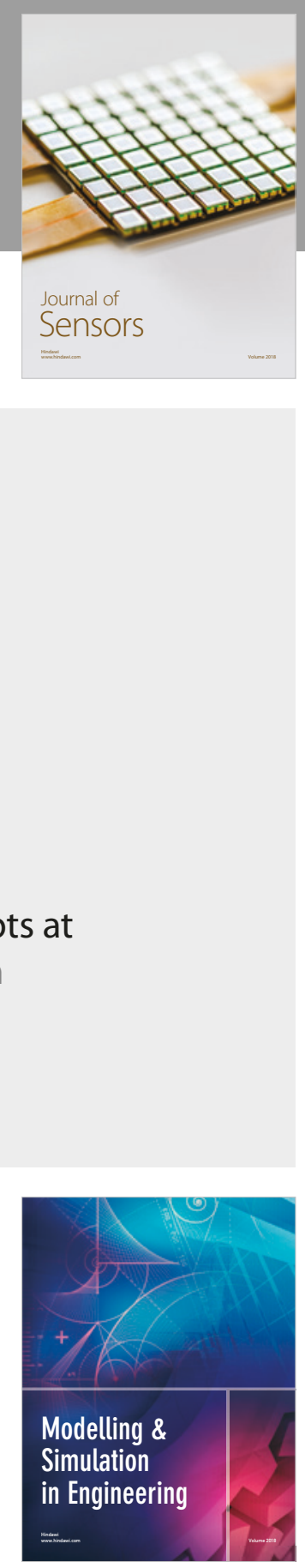

\section{Advances \\ Multimedia}
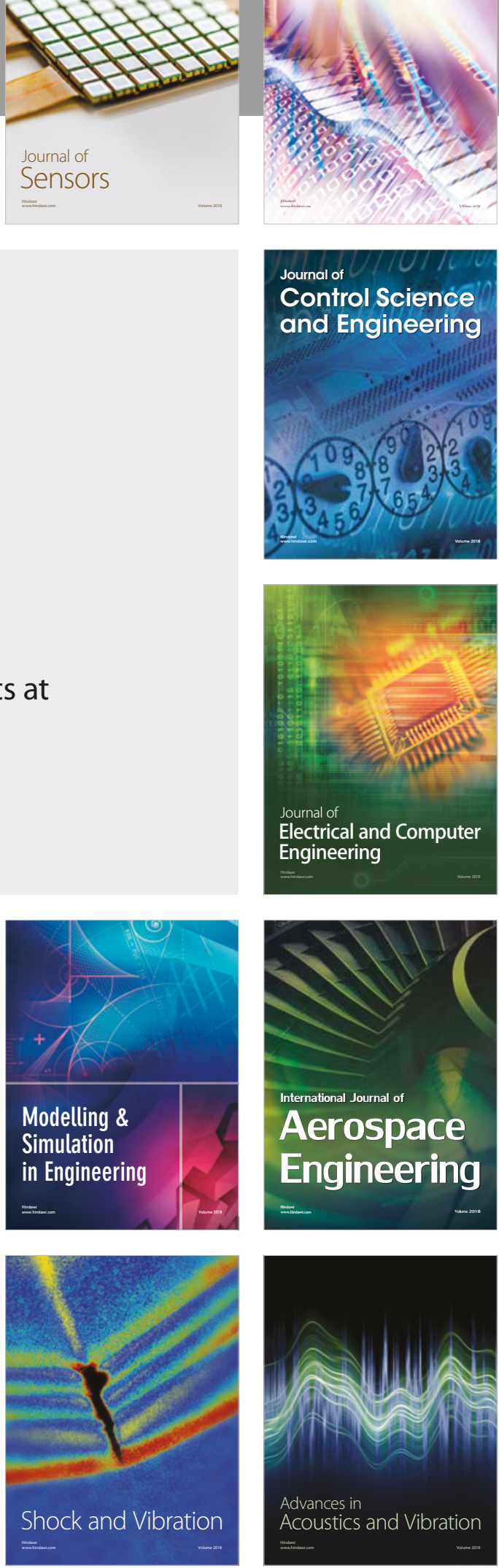